\title{
Educational Outreach to Opioid Prescribers: The Case for Academic Detailing
}

Margot Trotter Davis, $\mathrm{PhD}^{1}$, Brian Bateman, $\mathrm{MD}^{2}$, and Jerry Avorn, MD ${ }^{2,3}$

From: ${ }^{1}$ Brandeis University, Heller School for Social Policy and Management, Waltham, MA; ${ }^{2}$ Division of Pharmacoepidemiology and Pharmacoeconomics, Dept of Medicine, Brigham and Women's

Hospital, Boston, MA; ${ }^{3}$ Harvard

Medical School, Boston, MA

Address Correspondence: Margot Trotter Davis, PhD, LICSW

Brandeis University, Heller

School for Social Policy and Management 415 South St. Waltham, MA 02453

E-mail: margotd@brandeis.edu

Disclaimer: Brian Bateman is a paid consultant to Alosa Health. Conflict of interest: Each author certifies that he or she, or a member of his or her immediate family, has no commercial association (i.e., consultancies, stock ownership, equity interest, patent/licensing arrangements, etc.) that might pose a conflict of interest in connection with the submitted manuscript.

Manuscript received: 09-19-2016 Revised manuscript received: 12-13-2016 Accepted for publication: 01-03-2017

Free full manuscript: www.pain physicianjournal.com
Nonmedical use of opioid medications constitutes a serious health threat as the rates of addiction, overdoses, and deaths have risen in recent years. Increasingly, inappropriate and excessively liberal prescribing of opioids by physicians is understood to be a central part of the crisis. Public health officials, hospital systems, and legislators are developing programs and regulations to address the problem in sustained and systematic ways that both insures effective treatment of pain and appropriate limits on the availability of opioids. Three approaches have obtained prominence as means of avoiding excessive and inappropriate prescribing, including: providing financial incentives to physicians to change their clinical decision through pay-forperformance contracts, monitoring patient medications through Prescription Drug Monitoring Programs, and educational outreach to physicians.

A promising approach to educational outreach to physicians is an intervention known as "academic detailing." It was developed in the 1980s to provide one-on-one educational outreach to physicians using similar methods as the pharmaceutical industry that sends "detailers" to market their products to physician practices. Core to academic detailing, however, is the idea that medical decisions should be based on evidence-based information, including managing conditions with updated assessment measures, behavioral, and nonpharmacological interventions. With the pharmaceutical industry spending billions of dollars to advertise their products, individual practitioners can have difficulty gathering unbiased information, especially as the number of approved medications grows each year. Academic detailing has successfully affected the management of health conditions, such as atrial fibrillation, chronic obstructive pulmonary disease, and recently, has targeted physicians who prescribe opioids. This article discusses the approach as a potentially effective preventative intervention to address the epidemic of opioid overuse.

Key words: Opioid abuse, opioid misuse, academic detailing, health policy, interactive education, prevention

Pain Physician Opioid Special Issue 2017; 20:S147-S151 he use of opioids for the treatment of chronic pain conditions has become increasingly controversial due to limited data on long-term efficacy and the potential for addiction and other adverse health consequences associated with their use (1). During the 2000s, deaths from prescription opioid overdose increased approximately 3-fold and closely paralleled a rise in the total amount of prescription opioids dispensed (2). Of concern to the medical community and public health officials, is that more than half of the prescription opioid-related deaths occur at home, rather than in public or in a health care facility 
(3). The economic burden of treatment both in hospital emergency department visits and hospitalizations is also substantial: inpatient charges related to opioid abuse and dependence reached almost $\$ 15$ billion in the decade ending 2012 (4). Although the number of prescriptions of opioid analgesics vary state by state, the average is close to 85 prescriptions annually per 100 people, and states that have the highest number of prescription painkillers average up to 143 per 100 people (5). In 2012 hydrocodone was the most frequently dispensed prescription in the United States (5). To address this public health crisis, the American Pain Society issued recommendations for considerations when selecting analgesics to treat pain (6), and the Centers for Disease Control and Prevention issued a new set of guidelines to improve the way opioids are prescribed (7).

In spite of these efforts, prescription opioid misuse and dependence continue to have their origins in excessive or improper prescribing of medications by health care professionals (8-11). At the level of the clinician, opioid overprescribing may be the result of inattention to careful considerations of the risk and benefits of opioids for a particular patient or a lack of physician knowledge about appropriate alternatives to opioids for the treatment of pain. Generally, medical education is severely lacking regarding diagnosis and treatment of substance use disorders as well as abuse and diversion of controlled medications $(12,13)$. The failure to appreciate the potential risks associated with these drugs is a concern. A related component has been the aggressive promotional messages of some pharmaceutical companies promoting opioid analgesics, which overstated their indications and underestimated their potential for abuse, distortions which resulted in one manufacturer having to pay a legal settlement of over $\$ 600$ million for such improper promotional claims (14). Proposed solutions to the problem of overprescribing in primary care have included limits on the size of an initial opioid prescription, or allowing patients to choose to fill only a portion of the amount that could be dispensed $(15,16)$.

\section{Policy Levers to Address Over-prescribing}

However, it is vital to address the knowledge deficits and attitudes of prescribers that can lead to excessive opioid prescribing. Several policy levers are available to address the lack of knowledge and improve the clinical decision-making of physicians. Pay for performance has been used to influence clinical decision-making in several domains, but has had only limited success (17). It is unlikely to have a long-term effect in stemming the opioid crisis, and may have unintended consequences of encouraging practitioners to avoid patients who may possibly "spoil their numbers" (18). In addition, economic and ethical questions have also been raised about the concept of paying for a practice that should be routine $(19,20)$.

In relation to opioid use, prescription drug monitoring programs (PDMPs) are likely to offer greater utility. PDMPs monitor the dispensing of controlled substances, as defined by federal and state controlled substances laws, making it possible for prescribers to see whether a given patient is obtaining opioids from multiple clinicians or filling prescriptions at multiple pharmacies (21). Prescribers can access the database to determine if a patient has been "doctor shopping" for opioids (22) and can act as an early warning system for prescribers to avoid dangerous drug interactions and to ensure quality care (23). It is also useful for licensing boards that are investigating a licensee related to licensure, renewal, or disciplinary action. As of July 2014, 49 states and one territory had passed legislation authorizing a PDMP (24).

Both pay for performance and PDMPs fail to address one of the most important concerns regarding how to educate physicians on best practices. In one study, less than half of primary care physicians surveyed felt that they were sufficiently trained in prescribing opioids; younger providers were less knowledgeable about opioids (25). Concern is mounting that providers do not have access to information that will guide their prescribing and identify patients with high risk of abuse. The gap may not be filled adequately by existing prescriber education programs. One widely used continuing medical education initiative was prepared by the manufacturers of extendedrelease opioid products, as a requirement imposed by the Food and Drug Administration (FDA) for a Risk Evaluation and Mitigation Strategy, more commonly known as REMS, related to these products. However, in keeping with this origin, much of that material deals with the safe use of extended-release opioid analgesics. Another "light-touch" approach was initiated by Medicare in 2010 to educate prescribers of highly addictive drugs whose practices were outliers to peer-group providers. A randomized controlled study to evaluate the effects of sending educational letters showed no differences between the control and study groups (26). 


\section{Academic Detailing as an Approach to Educate Prescribers}

In the early 1980s, an approach known as "academic detailing" was developed to use the effective outreach and promotional strategies of the pharmaceutical industry (that is implemented through its sales representatives, or "detailers"), and apply it instead to transmitting the best evidence about optimal medication use, rather than simply to increase sales of a given product $(27,28)$. The approach is responsive to continuous quality improvement strategies (29) and diffusion of innovation theory to explain how innovations spread throughout groups (30). The approach is conducted through specially trained pharmacists, nurses, or physicians who are educated in the application of adult learning theory and behavior change, as well as in the details of the clinical problem being addressed. They are then sent to visit with physicians one-on-one in their offices, to present an interactive discussion of the most current evidence on proper drug use for that condition. The approach has been found to be effective in numerous randomized trials; a 2007 review of the literature by the Cochrane Collaboration assessed 69 randomized trials and concluded that the intervention was efficacious in improving prescribing (31). An early benefit-cost analysis found that such a program saved $\$ 2$ for state Medicaid programs for every dollar spent to implement it (32). Academic detailing programs have been established by several state departments of health and of aging, the US Department of Veterans Affairs (VA) health care system, large health care systems such as Kaiser, a number of Canadian provinces, and Australia (33-35).

Academic detailing has been applied to the problem of opioid misprescribing by several organizations. One of these is Alosa Health, a nonprofit organization founded in 2004. Through contracts with government agencies and health care systems, it assembles and integrates the most current evidence on optimal prescribing and then "markets" these recommendations to prescribers through interactive in-office education programs. Physicians receive continuing medical education credits for these educational outreach visits. Academic detailing strategies are especially useful to train doctors on the management of pain through a multifaceted approach that combines both nonpharmacologic and nonopioid pharmacologic treatment options. The nonbias approach to disease management has the potential to have large impact when it is applied systematically. For example, when the VA health care system, the larg- est health system in the United States, identified opioid misuse as one of the most important focal points for the academic detailing program, it began implementing academic detailing in VA sites throughout the country.

\section{Process to Evaluate Scientific Evidence}

In any academic detailing program, the process begins with a systematic review and synthesis of the most current peer-reviewed literature on optimal medication use and outcomes. As a case example, Alosa Health utilizes clinicians on the faculty of Harvard Medical School to conduct the rigorous reviews. The results of this review and its conclusions are then distilled into an evidence document that contains up to 100 references; its content emphasizes the implications of the evidence for front-line patient care decisions. This information is then distilled further into a graphically engaging $12-$ page color brochure that illustrates the prescribing recommendations with algorithms, tables, and graphs (36). A review of the literature on the role of opioids in pain management resulted in conclusions that were virtually identical to those stemming from the evidence synthesis and recommendations that the Centers for Disease Control and Prevention released 2 years later (7).

\section{Advantages of Interactive Education}

These data synthesis and "packaging" activities form the basis of the academic detailing intervention, but the most critical component of such programs is the interactive discussion of these concepts and recommendations with clinicians in their offices. This approach enables the well-trained outreach educator to understand the prescriber's current beliefs, attitudes, and practices, and to modify the presentation accordingly. In the case of encouraging more restrained use of opioids in primary care, for example, this interactivity makes it possible to determine whether the underlying problem for a given practitioner is lack of awareness of the addictive potential of these drugs, poor understanding of the potential of nonopioid drug treatments, an attitudinal problem that drug abuse is not the physician's primary responsibility, or other concerns. Often, it is a combination of these issues, as well as not knowing how to address "doctor-shopping." A skillful academic detailer uses the interactive educational presentation to address these specific issues in a targeted manner.

While there has been extensive evaluation of the effectiveness of academic detailing programs to 
improve medication use in other clinical settings, evaluation is still ongoing of its use to reduce overreliance on opioids for the management of pain in primary care. Recently, an FDA Advisory Committee recommended mandated training in opioid prescribing for all physicians (37). Academic detailing is likely to gain increasing interest as a means of implementing such training and thereby improving clinical choices in the area of opioid prescribing as it has in other clinical domains.

\section{Policy Implications and Recommendations}

Addressing the nation's epidemic of opioid overuse will require a wide variety of approaches, including legislation at the state and federal levels, programs implemented within public and private health care systems, and legal sanctions. However, in keeping with public health prevention strategies, one key component will have to be proactive education of prescribers to make sure that they have a full understanding of the risks of improper prescribing, as well as of how to manage patients who have or are at risk of opioid use disorder. The most effective programs may come at the state and local health care system levels.
There is considerable potential for policies that seek to improve physician prescribing practices as an effective way to prevent opioid dependence. A solid foundation of prescriber education will be an indispensable component of any effective nationwide program to stem the overuse of opioids. Academic detailing is one very promising approach to this problem; it has been shown in randomized controlled trials in numerous settings to provide physicians with evidence-based information in an interactive way that changes their prescribing practices.

Formal studies and benefit-cost analyses have not yet been done in relation to its application to addressing opioid misprescribing and should be supported by government funding such as the National Institutes of Health. If such "marketing" the best prescribing evidence to clinicians in a given health care system can prevent just one emergency department visit or intensive care unit stay for an overdose, or prevent one patient from becoming addicted because of an unwise choice of a pain regimen, its benefit in both human and economic terms is likely to far exceed its costs.

\section{References}

1. Portenoy RK PR, Passik SK. Lowinson JH, Ruz P, Millman RB, Langrod JG. Substance Abuse: A Comprehensive Textbook. 4th ed. Lippincott, Williams \& Wilkens, Philadelphia, 2004; pp 863-904.

2. Centers for Disease Control and Prevention. Vital signs: Overdoses of prescription opioid pain relievers: United States, 1999-2008. MMWR Morbidity and mortality weekly report 2011; 60:1487-1492.

3. Easterling $\mathrm{KW}$, Mack KA, Jones CM. Location of fatal prescription opioidrelated deaths in 12 states, 2008-2010: Implications for prevention programs. ] Safety Res 2016; 58:105-109.

4. Ronan MV, Herzig SJ. Hospitalizations related to opioid abuse/dependence and associated serious infections increased sharply, 2002-12. Health Aff (Millwood) 2016; 35:832-837.

5. IMS Health. The Use of Medicines in the United States: Review of 2011. IMS Institute for Healthcare Informatics, Parsippany, 2012.

6. Society AP, (ed). Principles of analgesic use in the treatment of acute pain and cancer pain. 6th ed. American Pain Society. Principles of Analgesic Use in the Treatment of Acute Pain and Cancer Pain.
Glenview, 2008.

7. Dowell D, Haegerich TM, Chou R. CDC Guideline for prescribing opioids for chronic pain: United States, 2016. JAMA 2016; 315:1624-1645.

8. Gwira Baumblatt JA, Wiedeman C, Dunn JR, Schaffner W, Paulozzi LJ, Jones TF. High-risk use by patients prescribed opioids for pain and its role in overdose deaths. JAMA Intern Med 2014; 174:796-801.

9. Baker JA, Avorn J, Levin R, Bateman BT. Opioid prescribing after surgical extraction of teeth in Medicaid patients, 20002010. JAMA 2016; 315:1653-1654.

10. Wunsch $\mathrm{H}$, Wijeysundera DN, Passarella MA, Neuman MD. Opioids prescribed after low-risk surgical procedures in the United States, 2004-2012. JAMA 2016; 315:1654-1657.

11. Carlson RG, Nahhas RW, Martins SS, Daniulaityte R. Predictors of transition to heroin use among initially non-opioid dependent illicit pharmaceutical opioid users: A natural history study. Drug Alcohol Depend 2016; 160:127-134.

12. O'Connor G. Doctors' role in the prescription abuse crisis. Addiction Professional 2010; 8:40-41.
13. Canada RE, DiRocco D, Day S. A better approach to opioid prescribing in primary care. J Fam Pract 2014; 63:E1-E8.

14. Meier B. In guilty plea, OxyContin maker to pay $\$ 600$ million. New York Times. May 10, 2007.

15. Bateman BT, Choudhry NK. Limiting the duration of opioid prescriptions: Balancing excessive prescribing and the effective treatment of pain. JAMA Intern Med 2016; 176:583-584.

16. Rubin R. Bill would permit partial filling of opioid prescriptions. JAMA 2016; 315:1443.

17. Rosenthal MB, Landrum MB, Robbins JA, Schneider EC. Pay for performance in Medicaid: Evidence from three natural experiments. Health Serv Res 2016; 51:1444-1466.

18. Gneezy U, Meier S, Rey-Biel P. When and why incentives (don't) work to modify behavior. J Econ Perspect 2011; 25:191-209.

19. Taub SJ. Pay for performance: Is it ethical? Compr Ophthalmol Update 2007; 8:277-283.

20. Wharam JF, Paasche-Orlow MK, Farber NJ, Sinsky C, Rucker L, Rask KJ, Figaro MK, Braddock C, Barry MJ, Sulmasy DP. 
High quality care and ethical pay-forperformance: A Society of General Internal Medicine policy analysis. J Gen Intern Med 2009; 24:854-859.

21. Bao Y, Pan Y, Taylor A, Radakrishnan S, Luo F, Pincus HA, Schackman BR. Prescription drug monitoring programs are associated with sustained reductions in opioid prescribing by physicians. Health Aff (Millwood) 2016; 35:1045-1051.

22. Morgan L, Weaver M, Sayeed Z, Orr R. The use of prescription monitoring programs to reduce opioid diversion and improve patient safety.] Pain Palliat Care Pharmacother 2013; 27:4-9.

23. Paulozzi LJ, Strickler GK, Kreiner PW, Koris CM. Controlled substance prescribing patterns: Prescription behavior surveillance system, eight states, 2013. MMWR Surveill Summ 2015; 64:1-14.

24. Prescription Drug Monitoring Program Center of Excellence at Brandeis University. Briefing on PDMP Effectiveness. September 2014 .

25. Jamison RN, Sheehan KA, Scanlan E, Matthews M, Ross EL. Beliefs and attitudes about opioid prescribing and chronic pain management: Survey of primary care providers. J Opioid Manag 2014; 10:375-82.

26. Sacarny A, Yokum D, Finkelstein A, Agrawal S. Medicare letters to curb overprescribing of controlled substances had no detectable effect on providers. Health Aff (Millwood) 2016; 35:471-479.

27. Avorn J, Soumerai SB. Improving drugtherapy decisions through educational outreach. A randomized controlled trial of academically based "detailing." $N$ Engl J Med 1983; 308:1457-1463.

28. Avorn J, Soumerai SB, Everitt DE, RossDegnan D, Beers MH, Sherman D, Salem-Schatz SR, Fields D. A randomized trial of a program to reduce the use of psychoactive drugs in nursing homes. N Engl J Med 1992; 327:168-173.

29. Van Hoof TJ, Meehan TP. Using theory and evidence to guide the use of educational outreach to improve patient care. Am J Med Qual 2012; 27:467-471.

30. Rogers EM. Diffusion of Innovations. Free Press, New York, 2003.

31. O'Brien MA, Rogers S, Jamtvedt G, Oxman AD, Odgaard-Jensen J, Kristoffersen DT, Forsetlund L,Bainbridge D, Free- mantle N, Davis DA, Haynes RB, Harvey EL. Educational outreach visits: Effects on professional practice and health care outcomes. The Cochrane database of systematic reviews. 2007; 4:CDoo0409.

32. Soumerai SB, Avorn J. Predictors of physician prescribing change in an educational experiment to improve medication use. Med Care 1987; 25:210-221.

33. Jin M, Naumann T, Regier L, Bugden S, Allen M, Salach L, Chelak K, Blythe N, Gagnon A, Dolovich L. A brief overview of academic detailing in Canada: Another role for pharmacists. Can Pharm J (Ott) 2012; 145:142-146.\}

34. NPSMedicineWise. Available from: www.nps.org.au.

35. Siegel D, Lopez J, Meier J, Goldstein MK, Lee S, Brazill BJ, Matalka MS. Academic detailing to improve antihypertensive prescribing patterns. Am J Hypertens 2003; 16:508-511.

36. Alosa Health. Opioids. www.alosahealth. org/modules/opioids/

37. Burton T. FDA Panel Urges Mandatory Opioid Training for Doctors. The Wall Street Journal, May 4, 2016. 
